\author{
Abstracta Iranica \\ Abstracta Iranica Revue bibliographique pour le domaine irano-aryen \\ Volume 32-33 | 2013 \\ Comptes rendus des publications de 2009-2010
}

\title{
Janet Afary (Guest editor). Iranian Studies, Special issue: On gender and sexuality
}

\section{Yoko Suzuki}

\section{(2) OpenEdition}

10 Journals

Édition électronique

URL : http://journals.openedition.org/abstractairanica/41038

DOI : 10.4000/abstractairanica.41038

ISSN : 1961-960X

\section{Éditeur :}

CNRS (UMR 7528 Mondes iraniens et indiens), Éditions de l'IFRI

\section{Édition imprimée}

Date de publication : 1 décembre 2013

ISSN : 0240-8910

\section{Référence électronique}

Yoko Suzuki, « Janet Afary (Guest editor). Iranian Studies, Special issue: On gender and sexuality », Abstracta Iranica [En ligne], Volume 32-33 | 2013, document 455, mis en ligne le 01 juillet 2016 , consulté le 27 septembre 2020. URL : http://journals.openedition.org/abstractairanica/41038 ; DOI : https://doi.org/10.4000/abstractairanica.41038

Ce document a été généré automatiquement le 27 septembre 2020.

Tous droits réservés 


\title{
Janet Afary (Guest editor). Iranian Studies, Special issue: On gender and sexuality
}

\author{
Yoko Suzuki
}

\section{RÉFÉRENCE}

Janet Afary (Guest editor). Iranian Studies, Special issue: On gender and sexuality. Vol. 42, $\mathrm{n}^{\circ}$ 1, February 2009, $176 \mathrm{p}$.

1 Sept chercheurs contribuent à ce numéro qui aborde les changements de la situation sociale des femmes et de la transfiguration des rapports entre les deux sexes, y compris l'homosexualité et la transgression sexuelle.

2 La promotion sociale des femmes iraniennes est si spectaculaire que de nombreuses chercheuses s'intéressent aux problèmes de "gender». Pourtant, comme nous le voyons dans ce numéro, de nombreux travaux se limitent à un discours sur les valeurs sociales, discours fondé sur des observations, des statistiques ou des droits mais qui ignorent l'aspect biologique ou la technologie qui peuvent être déterminants pour les valeurs et les fonctions des deux sexes dans une société.

Janet Afary, « Guest editor's note »;

Janet Afary, «The Sexual Economy of the Islamic Republic »;

Erika Friedl, « New Friends: Gender Relations within the Family »;

Mary Elaine Hegland, «Educating Young Women: Culture, Conflict, and New Identities in an Iranian Village »;

Fatemeh Etemad Moghadam, « Undercounting Women's Work in Iran »;

Nasrin Rahimieh, « Divorce Seen through Women's Cinematic Lens »;

Shahla Haeri, « Sacred Canopy: Love and Sex under the Veil »; 
10 Firoozeh Papan-Matin, "The Case of Mohammad Khordadian, an Iranian Male Dancer ».

\section{AUTEURS}

YOKO SUZUKI

Paris 